\title{
BMJ Open Impact of gender on the career development of female traditional Korean medicine doctors: a qualitative study
}

\author{
Se Eun Chun, ${ }^{\oplus 1}$ Ju Hyun Lee, ${ }^{2}$ Ju Eun Lee, ${ }^{3}$ Seung Min Kathy Lee, ${ }^{4}$ \\ Jungtae Leem, ${ }^{\oplus, 6}$ Hyunho Kim ${ }^{\oplus, 6}$
}

To cite: Chun SE, Lee JH, Lee JE, et al. Impact of gender on the career development of female traditional Korean medicine doctors:

a qualitative study. BMJ Open 2019;9:e030390. doi:10.1136/ bmjopen-2019-030390

- Prepublication history and additional material for this paper are available online. To view these files, please visit the journal online (http://dx.doi. org/10.1136/bmjopen-2019030390).

Received 12 March 2019 Revised 17 June 2019 Accepted 11 July 2019

Check for updates

(C) Author(s) (or their employer(s)) 2019. Re-use permitted under CC BY-NC. No commercial re-use. See rights and permissions. Published by BMJ.

${ }^{1}$ College of Korean Medicine, Dongshin University, Naju, Korea ${ }^{2}$ College of Korean Medicine, Dongguk University, Goyang, Korea

${ }^{3}$ College of Korean Medicine, Kyung Hee University, Seoul,

Korea

${ }^{4}$ Korean Medicine Science Research Center, Pusan National University, Pusan, Korea

${ }^{5}$ Chung-Yeon Central Institute,

Gwangju, Korea

${ }^{6}$ Dongshin Korean Medicine Hospital, Seoul, Korea

Correspondence to

Dr Hyunho Kim;

hyunho.kim@khu.ac.kr

\section{ABSTRACT}

Objective This study aims to examine the impact of gender and expected gender roles on the career development of young female traditional Korean medicine (KM) doctors.

Design We conducted semistructured interviews to examine the experiences of study subjects regarding early career choices, employment, job performance and career moves, as well as future career aspirations, from the perspective of gender. The transcription was analysed using the Strauss and Corbin constant comparative analysis method.

Setting The interview was conducted at a quiet and comfortable place selected by the participants in South Korea.

Participants Ten female KM doctors in their 30s participated in the study.

Results This study reveals that, initially, the participating female KM doctors were unaware of their gender affecting career decisions. However, after graduation and during employment, female doctors experienced direct discrimination or gender segregation while selecting areas of treatment and specialty; they found that they were preferred to work in paediatrics and dermatology departments than in departments treating musculoskeletal health problems. Furthermore, after entering the workforce, female KM doctors found that their gender significantly affects patient-doctor relationships and life events, such as pregnancy and childbirth require temporary career breaks. In addition, female KM doctors assumed stereotypical gender roles both in the workplace and at home, as well as becoming the main nurturer of their children.

Conclusion Gender and stereotyped gender roles affect the overall career planning, career moves and even patient-doctor relationships of female KM doctors. Female doctors were also more likely to experience specific gender roles in the workplace and at home, including both childbirth and childrearing.

\section{INTRODUCTION}

The number of female medical professionals is increasing worldwide. This is true in the field of traditional Korean medicine (KM) as well. In 2017, the ratios of numbers of female
Strengths and limitations of this study

- This is the first study to examine how gender affects the career progression of female Korean medicine (KM) doctors.

- By adopting the qualitative method, we could clarify the reality of gender discrimination issues prevalent in various sectors, such as employment, medical practice and career courses of female KM doctors.

- The study results provide insights into the education of and policy development for the medical workforce and will contribute to research on gender obstacles in medicine.

- This study does not reflect the experiences of female KM doctors living in relatively small villages, and only those people who could be contacted and who decided to participate in the study were self-selected.

traditional KM doctors and female allopathic medicine doctors to the total numbers of KM and allopathic medicine doctors in Korea were $21 \%$ and $25.4 \%$, respectively. ${ }^{1}$ Although this figure is lower than the world average $\left(46 \%^{2}\right)$, it reflects a significant increase compared with the ratio decades ago. In the field of KM alone, the total number of female KM doctors has increased from $2.4 \%$ in 1980 to $11.1 \%$ in 2000 and $21 \%$ in $2017 .{ }^{1}$ The number of female students being admitted in $\mathrm{KM}$ universities has increased to $37 \%$ in $2017,{ }^{3}$ and reports show that these numbers are expected to increase further.

However, according to the Global Gender Gap Report $2017^{4}$, South Korea was ranked 118 among 144 nations in the gender gap index ${ }^{4}$ and ranked the lowest in the glass ceiling index among the 29 Organisation for Economic Co-operation and Development countries. ${ }^{5}$ Earlier studies further support these data, since research indicates that the number of Korean women being hired in the labour market lag far behind that of 
Korean men. ${ }^{6}$ Although the number of women entering the professional workforce is increasing, more women with advanced academic degrees remain underemployed compared with their male counterparts, with a large number working on part-time jobs. ${ }^{7}$ Further, in South Korea and Japan alone, the employment to population ratio shows a characteristic 'M-shaped curve', 8 with less women in their 30s being hired during pregnancy and after childbirth. Even after being hired, female workers report experiencing discrimination, exclusion and tokenism as minorities in the industry. In the professional field, female physicians are assigned to low-ranking roles and have limited options in selecting their specialties, choosing their form of employment and exhibiting leadership. ${ }^{9}$ We observe this trend in the field of KM. A total of $77.98 \%$ practitioners work in local clinics; however, only $15.9 \%$ of all graduating female $\mathrm{KM}$ doctors are hired, and only $31.1 \%$ and $28.9 \%$ of these female KM doctors are hired by KM hospitals and general hospitals, respectively. ${ }^{10}$ Therefore, although the number of female KM doctors is increasing, they continue to experience exclusion in terms of employment and career development as well as experiencing discrimination.

Although such problems are widespread, insufficient research exists on gender discrimination in the KM field. An earlier study reported that women with advanced degrees have high career-related expectations during their first few years of employment; however, soon, they experience career limitations and change their career paths during pregnancy and childrearing. ${ }^{11}$ Another study showed that sociocultural factors such as fixed gender roles affect career advancement. Korean female interns and residents reported that they either hide their gender to gain more professionality or experience internal conflict while attempting to balance workplace and familial responsibilities. ${ }^{12}$ According to a report from Japan, where the workforce structure is similar to that of Korea, female doctors indicated poor working conditions and stereotypical gender roles as hindrances to continuing their careers. ${ }^{13}$

Hence, although the number of female practitioners in the KM field is increasing, they persistently encounter problems of discrimination in career development, and there is an urgent need to examine the factors underlying these problems. Therefore, in this study, we closely examine the experiences of female $\mathrm{KM}$ doctors by conducting semistructured interviews. We aim to clarify (1) the factors hindering career development and (2) gender roles affecting career choices, maintenance and advancement of female KM doctors.

\section{Cultural Context}

The Republic of Korea has a dualised medical system, which includes Western medicine (WM) and traditional KM. ${ }^{14} \mathrm{KM}$ is one component of the Traditional East Asian Medicine (TEAM), which encompasses the traditional medicine systems of Korea, China, Taiwan and Japan. The main therapeutic methods of TEAM include acupuncture, moxibustion and herbal medicine. ${ }^{15}$ TEAM has played an important role in medical service systems in East Asia. ${ }^{16}$ It developed as an aspect of national policies based on historical and cultural backgrounds differing from those of Complementary and alternative medicine $(\mathrm{CAM})$ in Western society. ${ }^{17}$

The differences between KM and CAM are as follows: first, unlike CAM, KM is considered a dual medical system with WM. According to the WHO's classification, the Korean medical system is the equalisation system, ${ }^{18}$ and the official licensing system in Korea includes both Doctor of Medicine and Korean Medicine Doctor (KMD). KMD is procured through a national medical licensing examination targeting only those who have studied both WM and KM at a 6-year KM medical school. Second, the major KM treatments are largely covered by national health insurance, unlike CAM treatments in the West, which are mostly covered by private health insurance. Third, KM includes a KM specialist system. The Ministry of Health and Welfare of Korea implemented the KM specialist system in 1999 by following the WM specialist system model. There are eight KM specialties, including acupuncture and moxibustion, internal medicine, gynaecology, paediatrics, ophthalmology-otorhinolaryngology-dermatology, neuropsychiatry, rehabilitation medicine and Sasang constitutional medicine.$^{19}$ However, KM general practitioners practising in local clinics are expected to treat cases under most of these specialties. Furthermore, some WM and KM specialty treatments have been developed in conformance with the prevalent sociocultural environment. For example, appearance-based discrimination is widespread in contemporary Korean society and, hence, aesthetic medicine is extensively practised in local clinics. ${ }^{20}$

Another important consideration in the current study is that the Republic of Korea, which technically continues to be at war with North Korea, mandates conscription for all men. Accordingly, male doctors in South Korea must serve in a public health centre for 3 years to complete their mandatory military service. Since women are not eligible for drafting in the country, female doctors immediately begin their career after graduation. Therefore, Korean doctors generally encounter gender difference during their initial career development phase due to such special circumstances.

\section{MATERIALS AND METHODS Participants}

The subjects of this study included female KM doctors and board-licensed specialists of clinical medicine in their 30s (as of February 2018). We informed the participants of the study and obtained their consent. The inclusion criterion was to include female $\mathrm{KM}$ doctors in their $30 \mathrm{~s}$ since, according to earlier studies, this is the age range corresponding to the breakaway of the highest number of female workers from the workforce, and this age group best reflects the aim of this study. ${ }^{8}$ Considering the career 
difference between the medical practice and the medical education, the subjects include only medical practitioners in clinical medicine as well. A purposive sampling method was used to recruit participants with the help of personal contacts of researchers, KM college professors and the Association of Women Korean Medical Doctor. On completing the interview, the participants were asked to recommend other participants who could provide a different perspective (snowball sampling). Further, the theoretical sampling approach was used to select the next participant for the interview. Finally, data collection continued until all the researchers agreed that data saturation had occurred.

\section{Study design}

All the participants were provided a detailed explanation of the research protocol, including the study purpose, study method, protection of private information and participant rights. Further, the participants were notified that their interviews would be digitally audiotaped and that they could stop the interview whenever they felt uncomfortable with the topics being discussed. In addition, this study was designed based on the symbolic interactionism and intersectionality theory. According to the former, the human self is actively creating meaning to the world, and these meanings are undergoing constant change because they are being defined and redefined by human interaction. ${ }^{21}$ On the other hand, the intersectionality theory suggests that various social identities such as gender, class, age and culture dynamically act together in human beings and that mutually constitutive relations of these identities explain specific forms of social oppression. $^{22} 23$

\section{Data collection}

Data collection was performed from 11 February, 2018 to 14 July 2018 . The in-depth face-to-face interview was conducted in Korean using a semistructured interview guide at a quiet and comfortable place selected by the participants. The open-ended questions were selected and refined during a pilot study that was conducted before the main trial and, subsequently, the adequacy of the questions was checked. The questions were divided into different categories based on career planning and employment, job performance, career moves and future plans. Participants' experience for each category was collected. Within 24 hours of the interview, participants were followed up through telephone to check whether they could provide any additional information. All the interviews were conducted by two researchers (SEC and JHL), and each interview took $37-99 \mathrm{~min}$ ( $59 \mathrm{~min}$ on average) to complete.

\section{Analysis}

After each interview, the interview was transcribed verbatim by three researchers (SEC, JHL and JEL) and double checked by one researcher (SEC). The transcribed data were analysed line by line using the Strauss and Corbin constant comparative analysis (CCA) method. This method was selected to systematically interweave the perspectives of the researchers and study participants and used to create a modified version. Using the CCA, the collected data were analysed based on the data itself, which helped maintain the insider's perspective, enabling us to understand the meaning given by research participants. ${ }^{24}$ In addition, the theoretical framework applied by the researcher enables the constant comparative process, which causes the introduction of the outsider's perspective into the study. ${ }^{25}$ To identify the initial concepts, experiences that were significantly related to gender were labelled, resulting in categories and subcategories, which were grouped according to their relationship with the concepts (open coding). Further, coding was performed using MAXQDA 2018 (VERBI GmbH, Berlin, Germany) to reduce the methodological errors that may occur when coding is performed by hand. ${ }^{26}$

\section{Validity and reliability}

This study was designed and conducted according to the Consolidated Criteria for Reporting Qualitative Research (see online supplementary document). ${ }^{27}$ To increase the validity of the sampling process, the researchers purposefully selected participants from different backgrounds to ensure that the study considers a variety of different experiences. Researcher bias was reduced by bracketing possible assumption, ${ }^{28}$ and the thoughts and interpretations that arose during analysis were meticulously recorded to maintain a valid perception throughout the process. ${ }^{29}$ After coding the data, a participant was randomly selected to review the results and verify the accuracy and objectivity of the analysis process. ${ }^{30}$

Two bilingual translators translated and proofread the original Korean transcripts into English. In case of areas that were ambiguous, a third translator was consulted to select a translation that best retained its original nuance.

\section{Patient and public involvement}

Before starting the study, we performed a pilot interview on a female professional in her thirties to test the interview design and, subsequently, made minor changes to the interview questions. This interview was not included in the study. There was no further involvement of the patient and public in the design or conduct of the study. Further, a lay summary of the study's findings will be disseminated to study participants.

\section{RESULTS}

\section{Participants' characteristics}

Overall, 12 eligible KM doctors were contacted to attend the interview, of whom two declined due to personal reasons. By July 2018, a total of 10 subjects consented to participate and were, subsequently, interviewed for this study. Among the participants, there were more general practitioners than specialists; however, half of the participants had experience working as interns or residents in 
Table 1 Basic characteristics of study participants

\begin{tabular}{llllll}
\hline Code & Age & $\begin{array}{l}\text { Date of acquiring } \\
\text { certification }\end{array}$ & Type of certificate & Current workplace & Current designation \\
\hline$\# 001$ & 37 & 2006 & GP & Unemployed & \\
$\# 002$ & 32 & 2010 & Specialist & Doctor's office & Owner \\
$\# 003$ & 36 & 2011 & GP & Doctor's office & Owner \\
$\# 004$ & 37 & 2007 & GP & Doctor's office & Employee \\
$\# 005$ & 33 & 2009 & GP & Doctor's office & Employee \\
$\# 006$ & 32 & 2010 & GP & Doctor's office & Owner \\
$\# 007$ & 35 & 2008 & GP & Doctor's office & Owner \\
$\# 008$ & 36 & 2007 & Specialist & Doctor's office & Owner \\
$\# 009$ & 34 & 2007 & Specialist & Hospital & Employee \\
$\# 010$ & 36 & 2006 & GP & Doctor's office & Owner \\
\hline
\end{tabular}

GP, general practitioner.

hospitals. At the time of conducting the study, most of the interviewees were working as primary physicians in their own local clinics; however, a few were employed at a hospital and one was taking a break and is currently unemployed. Further, 8 out of 10 participants were married, and half had children. Table 1 depicts the participants' basic characteristics.

\section{Analysis results}

The analysis generated 6 categories, 14 subcategories and 27 concepts. The emerging categories were (1) initially unperceived gender differences, (2) gender segregation in $\mathrm{KM}$ practice, (3) gender-related aspects that affect patient-doctor relationships, (4) suspended career or career movement caused by life events, (5) fixed gender roles and (6) maintenance and pursuit of a career. The gender-related experiences of female $\mathrm{KM}$ doctors in selecting their career paths and advancing in them are described for each category.

\section{Initially Unperceived Gender Differences}

According to most participants, gender differences did not affect career planning during their medical school years. Although some career choices were made based on their gender, they did not perceive gender as being a decisive factor. Participants said that they mapped out their careers after considering occupational characteristics and personal life conditions.

At the time, my gender being a woman didn't really affect how I planned my career. (\#006)

The more important factor affecting career choice was one's concern over her possible lack of ability as a doctor. Some participants answered that their own sense of purpose or limited career options affected their initial choice, whereas a few said that work experience as a student and age affected career decisions, as well.

Most of the male students went on to work as public health doctors, people who were older opened their own clinics, and young female students only made up $20 \%$ of all the 100 students at our school. All 20 of them applied to work at a hospital, including me. (...) I had no choice but to work as an intern since I didn't have a lot of options to choose from. (\#001)

\section{Gender segregation in KM practice}

In addition, gender segregation in KM practice stands out as a significant factor affecting female KM doctors' career decisions and employment.

\section{Career paths recommended for female KM doctors}

The majority of the participants answered that there were some specific career paths that were either recommended or not recommended for female KM doctors.

Just because I am a woman, am young, and had just graduated, I was advised that running a clinic wouldn't work out, and to not open my own clinic, (...) or to choose to work in the area of aesthetics like skin care or weight loss (Aesthetic KM is similar to aesthetic medicine in WM. The therapeutic methods of aesthetic KM include acupuncture for skin care and herbal medicines acting as appetite suppressants for weight loss, and so on). I just got a lot of advice of that kind. But ... how can I put it, they hurt my pride as a doctor and, on hearing those remarks, it seemed like they assumed that I would be interested in aesthetics just because I am a woman. (\#005)

\section{Employment followed by gender segregation}

The majority of the participants experienced gender segregation in KM practice while finding employment. Female KM doctors were preferred in departments such as $\mathrm{KM}$ dermatology and $\mathrm{KM}$ paediatrics, whereas their corresponding male counterparts were better preferred in the department of acupuncture and moxibustion, the department of rehabilitation and local clinics. 
Usually, female Korean medicine doctors are preferred and wanted by Korean medicine clinics that specialize in aesthetics like skin care and weight loss but those specializing in pure traditional Korean medicine prefer male doctors. (\#007)

Most Korean medicine clinics that use a lot of acupuncture don't prefer female doctors. When I attended my job interview, they did not look pleased and said to me, "Can you even bear to work standing up all day?" (\#001)

A few participants followed such gender segregation rules and succeeded in becoming employed. In other words, in women-centred, segregated specialties, some participants had an advantage in securing employment during the early days of their career. The others deviated from the expected roles and, hence, experienced difficulties in becoming employed. A few others initially deviated from the expected roles but later conformed with the roles to specialise in the fields recommended for female professionals. This was because their bosses required them to be in charge of such fields, and they ultimately experienced mixed stability and insecurity in their career.

It was not like I wanted to work in pediatrics. When I saw the job ad, the job descriptions weren't particularly about dieting or children's illnesses. It was just that as I was working there, I was asked (to focus on the area of pediatrics) by the doctor who had hired me and I, being a woman, worked out well, so I cared more about that kind of illness. (\#006)

Gender-related aspects that affect patient-doctor relationships Most of the participants mentioned that they had encountered situations where their gender affected the patientdoctor relationship. More than half of them answered that they had experienced patients being aware of the doctor's gender.

I often hear patients say, "huh, the doctor is so young. The doctor is a woman." That really happens. They just say that in my face. "Oh, you are a woman." (\#005)

Further, female KM doctors mentioned that they could better relate to female patients and said that this worked as an advantage. Patients had a tendency to feel more at ease with a female $\mathrm{KM}$ doctor. This tendency has both positive and negative effects.

Patients want to be able to talk about themselves comfortably with doctors at Korean medicine clinics. (...) And being a female doctor has its advantages because patients tend to talk more comfortably with female doctors. (\#003)

But there are also some male patients who talk down to female doctors from time to time. (\#009)

A few participants had experienced situations where patients seemed to feel more comfortable with body exposure because the doctor was a woman. However, sometimes, patients did not treat them as KM doctors and sexually objectified or harassed them in the clinic.

People just assume that most of the Korean medicine doctors are old or they think it is acceptable if the doctors are young male doctors. But when I come into the room, some old ladies say, "where is the doctor? Tell the doctor to come and not the nurse." (...) I was once called "unni," which means an older sister in Korean. "Hey, my kid is sick. Unni, do you recommend me feeding so and so to my kid?" (\#001)

There were one or two cases when our staff were (harassed). The patients would do that to the staff (...). Sometimes, they would do that to me too. A female doctor (...). They would ask me to touch them, or joke about my figure, or remark about it. For instance, saying stuff like "well doctor, you are in better shape than I had imagined." (\#007)

\section{Suspended career or career movement caused by life events}

Half of the participants had experienced pregnancy and childbirth and been directly affected by these life events. In cases where the female KM doctors were self-employed and were managing their own clinics, they had to take a career break, hire a part-time doctor to fill in for their positions and come back after a fixed period following pregnancy/childbirth. If these doctors were employed at a local clinic or a hospital, all had to resign from their positions. Following resignation, female KM doctors experienced significant career breaks equal to the amount of time that was spent giving birth and receiving postnatal care. The length of this period showed individual variations, since some went back to work or opened their own clinics, whereas others experienced longer delays following childrearing or second childbirth. In case of planned pregnancy or childbirth, female KM doctors opted to change jobs or make career plans with their possible pregnancy in mind. Some mentioned the difficulties of obtaining maternity leave, particularly in the medical profession.

As I was planning for my pregnancy, I found a relatively easy position at a nursing home, and I quit after working for 6 or 7 months. (\#001)

Big corporations have a lot of subs available; however, even in big hospitals, subbing for someone isn't easy. It means that someone new has to be hired since the other workers are not that flexible in terms of schedule to cover another person's work. (\#003)

Meanwhile, these life events had an effect on the employment process and, for some, they were hindrances to career advancement.

During the job interview, there were two other female doctors and we were all asked during the interview whether we had a boyfriend. I wonder if they asked that kind of question to the male doctors, as well. We were also individually asked if we had a boyfriend or 
whether we were planning to get married any time soon. They really did. So I said no. Two other female doctors and I talked about it afterward, saying that if we are asked about such things, the answer must always be "no." (\#008)

\section{Fixed gender roles}

Many female KM doctors witnessed their male counterparts being favoured during the employment process. As women, they experienced having to become the main nurturer of children at home.

\section{Direct discrimination during employment}

The majority of the participants answered that they felt male doctors were preferred by employers. Sometimes, male KM doctors were preferred over female doctors in the fields that were unrelated to the gender segregation prevalent in $\mathrm{KM}$ or that were known to prefer female doctors. Further, some participants felt that objective job performance indicators were not examined during the employment process.

I was asked to post a job ad for my replacement and was asked to include three requirements; must be male, someone who is not too young, and from OO University. Actually, I don't fulfill any of these requirements. I understand that doctors with these qualities are likely to be preferred, but I was thinking whether all that was necessary. (\#008)

Although I was a female resident, I think I wanted to show that I was capable of continuing my job at the hospital. So, in the last year as a resident, I really worked hard and performed my best comparedto my fellow residents, which resulted in the highest rate of returning patients and making the most profit for the hospital. But, unfortunately, it turned out that my efforts didn't mean much because I was a woman. I am sure if I were a man, things would have turned out differently. Men would have been given the privilege to apply to a director position at a hospital. (\#002)

Occasionally, some participants reported cases where the employers preferred to hire a female doctor over a male one. Usually, this trend was observed when the predecessor had been a female employee or the workplace required attitudes based on stereotyped feminine roles.

That doctor (employer) seemed to think that he lacked a gentle personality and you know there are patients who like that kind of personality? So I think he hired me (to make up) for that image. (\#009)

\section{Role of becoming the main nurturer}

Half of the female KM doctors participating in this study had experienced childbirth and responded that they were the person in charge of childrearing at home. All of them expressed difficulties in managing the work-family balance. Some of them mentioned that their additional job of having to care for the children significantly infringed on their personal time for self-improvement, such as studying and attending continuing education programmes as KM doctors.

At first, it was physically overwhelming; so for about a year, I really thought about it really much, on whether I should continue working or whether I should focus more on my duties as a mom and a wife. (\#002)

On the other hand, the majority of the female KM doctors with children also said that they voluntarily took on the role of the main nurturer out of maternal affection. Further, many of the participants without children perceived that they would become the main nurturer of their children in the future.

\section{Maintenance and pursuit of a career}

Almost all the study participants had had optimistic career expectations while making their career plans at the start of their careers. They were the generation called the 'Highest College Scholastic Aptitude Test Generation' (students during the 1990s and early 2000s had to score the highest range of the Korean college scholastic aptitude test to gain entry to any of the KM universities). They had not been concerned about their future as KM doctors and had had high expectations and great ambitions regarding their future careers.

(Scores had to be) Very high. Very high. I entered the medical school as the class of 2006 (entering in the year 2000) and that was when getting into a KM university was most rigorous. (\#001)

When I was an undergraduate, I was really ambitious and had big dreams, such as spreading Korean medicine worldwide (laughs). Hmm, yes I had those dreams. (\#002)

After becoming employed, most of the female KM doctors changed jobs in pursuit of self-development, and more than half of the participants answered that their ultimate goal is to become better professionals or develop specialties in their field. The specialties that the participants intended to develop themselves intended to be related to their gender roles. A few answered that they wished to operate a stable business and balance their work-related and familial duties. While discussing their present and future career goals, participants tended to maintain a grip on reality and make corresponding adjustments to their career goals.

Now, I don't want something that grandiose. Rather, I would like to think about the people that need my help or has received my help. Right, being able to provide better care for the people that come to me in need and to be a better doctor, that is my current goal. (\#004) 


\section{DISCUSSION}

In this study, we examined how gender and gender roles affect female KM doctors' career choices, advancement and maintenance by conducting in-depth interviews and qualitatively analysing the results. This study revealed that gender segregation in KM practice affects career decision paths, employment and job positions of female KM doctors even after they become employed. The existence of gender segregation in the medical profession has been previously noted. According to the Association of American Medical Colleges 2015 report on active physicians by sex and specialty, the highest number of female physicians occurs in paediatrics $(61.9 \%)$, obstetrics and gynaecology (54.5\%), and paediatric haematology/oncology (51.9\%), whereas that of male doctors was in orthopaedic surgery $(95 \%)$, thoracic surgery $(94 \%)$ and interventional cardiology (92.6\%). ${ }^{31}$ Although no such report exists in the KM field, a noteworthy survey among graduating students revealed that students perceived male KM doctors would be favoured in the departments of KM rehabilitation, acupuncture and moxibustion and KM internal medicine, whereas female KM doctors would be favoured in $\mathrm{KM}$ obstetrics and gynaecology, KM paediatrics and KM ophthalmology-otorhinolaryngology-dermatology. ${ }^{14}$ However, one difference is that the number of doctors who attend further training in different specialties is only $11.7 \%$ (as of 2016) in the field of $\mathrm{KM}^{32}$; however, even then, gender segregation is highly prevalent among general practitioners. The lack of adequate competence and skills is another reason why female $\mathrm{KM}$ doctors do not select a specific career path, which was frequently mentioned by interviewees, who described this as 'lacking sufficient clinical experience'. A Dundee Ready Educational Environment Measure survey among KM university students showed that the students' perception of learning scores related to their competence were low $^{33}$; further, in the study by Nomura et $a l^{34}$ female medical students showed lower confidence in clinical and academic competitiveness compared with their male colleagues.

Female KM doctors experienced fixed gender roles during employment and in work-home environments. Their male counterparts were generally preferred during the employment process, and this finding agrees with previous studies. In a 'Sense of gender division of labour survey' conducted among physicians in South Korea, more than half of the respondents answered that if they had the authority to select new physicians or residents in hospitals, they would select male doctors. ${ }^{9}$ A survey conducted among students graduating from a KM university revealed that students preferred to work with male colleagues in the future.$^{35}$ Further, a study by McKimm et $a l^{36}$ revealed that traditional stereotypes on medical leaders and their behaviours are biassed in favour of men, and a culture based on such masculine styles of leadership can devalue women so that many women may choose not to apply for leadership positions. Maternalism is another major reason why female KM doctors take the lead in becoming the main nurturer at home. Further, Heo's panel analysis ${ }^{37}$ of gender role attitudes among women aged 24-37 years in South Korea revealed that although the ideology of gender division of labour has become diluted, attitudes on childrearing remain unchanged. Female KM doctors were no exception to taking career breaks during and after childbirth; this trend coincides with the characteristic M-shaped curve, reflecting the employment-population ratio of women that is observed only in South Korea and Japan. Most of the participants felt that childbirth had a bigger impact on their careers than marriage. Eun $^{38}$ reported that, in South Korea, whereas the percentage of women quitting the workforce after marriage was low, the corresponding numbers increased following childbirth. In Japan, many female physicians resigned from full-time hospital jobs within 10 years of graduation since they could not manage long working hours, the lack of substitute doctors and the added burden of childcare ${ }^{39}$ In this study, the career moves made by women after childbirth breaks ranged from opening their own full-time clinics to taking time off from work; this result is different from that of an earlier study. ${ }^{40}$ Even when female KM doctors opened their own clinics, such decisions were often the result of having limited options after childbirth or were a demand due to flexible work hours.

Despite experiencing gender discrimination, most female KM doctors maintained their career goals by making small adjustments in the development process. To maintain the work-family balance, many were forced to shorten their work hours; however, even in these situations, the study participants chose to retain their careers rather than quitting the labour market, which is different from the results of other studies ${ }^{13}$ examining the perception of career pursuits among female physicians; this is also different from the 'leaky pipeline phenomenon' noticed among female workers in science, technology, engineering and mathematics (STEM) fields. The difference shown by our results may be attributed to the fact that the participants in this study consist of female KM doctors from different economic backgrounds who formed a remarkable generation in the history of KM. Another interesting result was that some participants in this study frequently answered that their gender as a woman does not matter to them and that it did not affect their career, although interview results revealed otherwise. This finding conformed to the finding by Smith et $a l^{41}$ Further, Kim et $a l^{42}$ noted that people in disadvantaged groups, such as women or less-educated workers in South Korea, tend to report less discrimination for themselves compared with men or higher educated workers, respectively.

Another noteworthy aspect of this study is that the gender of all the female participants affected clinic-based patient-doctor relationships. Gender was associated with other factors, such as age and culture. Studies have shown that demographic factors and socioeconomic factors can influence patient-doctor relationships ${ }^{43}$; however, the prevalence of gender as a factor is a recent phenomenon in South Korea. The finding that the female KM doctors 
in our study related particularly well with female patients has been noted by other studies. According to a report by Bertakis, ${ }^{30}$ doctors report a high degree of understanding and patients feel a high level of comfort when both are of the same gender. In a study by Schieber $e t a l^{44}$ researchers showed that patients more easily accepted doctor's recommendations when both were of the same gender. Interestingly, the female KM doctors in our study answered that male patients seemed to feel more comfortable with female doctors and tended to reveal sensitive health issues to the latter. However, other studies have shown that, if given an option, male patients choose male doctors over female doctors ${ }^{45}$; however, Himmelstein and Sanchez ${ }^{46}$ further noted that men of strong masculinity tend to report fewer symptoms to male doctors than female doctors. Jefferson et al also revealed that social expectations of how female doctors should behave may lead patients and female doctors to spend more time on psychosocial communication, reinforcing the gender role. $^{47}$ Regarding sexual objectification and harassment, the South Korean Medical Association reported in 2017 that $45.5 \%$ of female residents experienced sexual harassment in the healthcare workplace. ${ }^{48}$ There is no published survey on the training and working conditions of KM female doctors, and our study shows that such investigations are urgently required.

This study has several limitations. Globally, gender is a sensitive topic in all male-dominated fields, including the medical profession; hence, the participants could have been prone to providing desirable answers. However, some of these answers enabled meaningful discoveries in this qualitative study; an example is the participants' constant denial of gender being a career barrier. Although participants were recruited through several channels and purposefully sampled to incorporate as many different experiences as possible, most of them were located in the metropolitan area of South Korea, and their experiences may differ from those of female KM doctors living in smaller villages. In addition, only those participants who could be contacted and could consent to participate were self-selected. Although this ensured compliance with research ethics, the study might have missed those who were unwilling or unable to share their career experiences and those who had already left the medical workforce. Since such limitations may exist, further studies are required to confirm whether the study's results can be generalised to larger populations. However, to the best of our knowledge, this is the first qualitative study to examine the effect of gender on the careers of female KM doctors, and we believe that this study provides significant information for future studies on the provision of gender sensitive education to KM university students and development of improved working conditions and policies for female professionals working in STEM-related fields.

\section{CONCLUSIONS}

Over the past 40 years, the number of women working in KM healthcare has increased, and this trend is expected to continue. Problems related to the gender gap are also expected to increase, particularly among female professionals working in the KM field. This study was designed to examine the difficulties encountered by female KM doctors in terms of employment, job performance and career maintenance, and we revealed significant gender-specific factors. Our study revealed that during employment, strong stereotypical gender roles directly or indirectly affect the employment process. In the medical field, female KM doctors pursued paediatrics, dermatology and similar areas of specialised care, whereas their male counterparts focused on departments of acupuncture and moxibustion, rehabilitation and general KM clinics. Our study participants showed a tendency to maintain their career pursuits; however, their pursuits were limited by important life events, such as childbirth. Female KM doctors maintained maternalism notions that made them conform to standardised gender roles at home. Further, gender significantly affected patientdoctor relationships. Female KM doctors could relate more with patients of the same gender. Finally, although this study has limitations, it is a valuable resource for future large-scale quantitative studies.

Acknowledgements The authors thank all the study participants for their participation in the semistructured interviews.

Contributors All authors (SEC, JHL, JEL, SMKL, JL and HK) contributed to the conceptualisation and design of the study, and reviewed and approved the final manuscript. HK is the corresponding author. SEC and JHL conducted the interviews SEC, JHL, JEL and HK contributed to the analysis and interpretation of the data. SMKL translated the original Korean transcripts into English. SEC wrote the original draft and made a final manuscript.

Funding The authors have not declared a specific grant for this research from any funding agency in the public, commercial or not-for-profit sectors.

Competing interests None declared.

Patient consent for publication Not required.

Ethics approval This study was approved by the Korea National Institute for Bioethics Policy (grant no: P01-201808-22-010).

Provenance and peer review Not commissioned; externally peer reviewed. Data availability statement Data are available upon reasonable request.

Open access This is an open access article distributed in accordance with the Creative Commons Attribution Non Commercial (CC BY-NC 4.0) license, which permits others to distribute, remix, adapt, build upon this work non-commercially, and license their derivative works on different terms, provided the original work is properly cited, appropriate credit is given, any changes made indicated, and the use is non-commercial. See: http://creativecommons.org/licenses/by-nc/4.0/.

\section{REFERENCES}

1. Statistics Korea. The lives of women as reflected in 2018 statistics. Seoul: Statistics Korea, 2018.

2. OECD. Health at a glance 2017: OECD indicators. Paris: OECD Publishing, 2017.

3. Korean Ministry of Education, Korean Educational Development Institute. Statistical yearbook of education 2017. Chungbuk, Republic of Korea: Korean Ministry of Education, 2017.

4. Schwab K, Samans R, Zahidi S, et al. The global gender gap report 2017. Geneva: World Economic Forum, 2017. 
5. Data Team of The Economist. The glass ceiling index. The Economist 2018;426.

6. Choi SE. What makes it difficult for Korean high educated women to participate in the labor market? The heritage of the developmental welfare production regimes of Korea. Issues in Feminism 2017;17:145-92.

7. Son SY. Labor experiences and dilemma of highly-educated professional women in Korea. Korean Association of Women's Studies 2005;21:67-97.

8. Cho YY. Childbirth and labor supply for married women: lifecycle model. Sejong-si, Republic of Korea: Korea Development Institute, 2006: 5-11.

9. Kim SH. The gendered structures and status of female doctor in Korean healthcare institution. Pusan, Republic of Korea: Pusan National University, 2004.

10. Health Insurance Review \& Assessment Service,, National Health Insurance Service. National health insurance statistical year book. Seoul: National Health Insurance Service, 2016.

11. Ahn JH. The influence of gender on ProfessionalismFemale in trainees. Korean J Med Educ 2012;24:153-62.

12. Son JH. Career experiences of highly educated professional women: focusing on women with 5-10 career years. Korea Journal of Counseling 2013;14:501-22.

13. Nomura K, Yamazaki Y, Gruppen LD, et al. The difficulty of professional continuation among female doctors in Japan: a qualitative study of alumnae of 13 medical schools in Japan. BMJ Open 2015;5:e005845.

14. Lee H-Y, Kang H-W, Kim N, et al. Effectiveness of Collaborative treatment using Korean and Western medicine for mild cognitive impairment or dementia: a protocol for a prospective observational exploratory study. Medicine 2018;97:e12098.

15. Cheung F. TCM: made in China. Nature 2011;480:S82-3.

16. Sung HJ, Shin HK. Comparison and research on policy of rraditional medicine in Korea and three countries of East Asia, Daejeon. Republic of Korea: Korean Institute of Oriental Medicine, 1997.

17. Ryu GC, Lee HW, Oh SJ, et al. International competitiveness and tasks of Korean traditional medicine from the perspective of international comparison of curricula and research. Journal of Korean Institute for Health and Social Affairs 2005;25:107-46.

18. Yoon KJ, Kim DS. Ways of integrating Oriental medicine and Western medicine. Sejong-si, Republic of Korea: Korea Institute of Health and Social Affairs, 2013.

19. Park H-L, Lee H-S, Shin B-C, et al. Traditional medicine in China, Korea, and Japan: a brief introduction and comparison. Evid Based Complement Alternat Med 2012;2012:1-9.

20. Yun Y-M, Jung SH. Trajectories of appearance concerns of South Korean adolescents. J Health Info Stat 2018;43:245-54.

21. Aldiabat KM, Le Navenec CL. Philosophical roots of classical grounded theory: its foundations in symbolic interactionism. Qual Rep 2011;16:1063-80.

22. Shields SA. Gender: an intersectionality perspective. Sex Roles 2008;59:301-11.

23. Wilson $Y$, White $A$, Jefferson $A$, et al. Intersectionality in clinical medicine: the need for a conceptual framework. Am J Bioeth 2019;19:8-19.

24. Jennifer CS, Mills J, Usher K. Linking symbolic interactionism and grounded theory methods in a research design: from Corbin and Strauss' assumptions to action. SAGE Open 2013;3:1-10.

25. Fram SM. The constant comparative analysis method outside of grounded theory. Qual Rep 2013;18:1-25.

26. Lee SM, Yang SP, Kim ES, et al. Admission care for Bell's Palsy patients: A qualitative report on patient experiences. The Acupuncture 2013;30:11-23.

27. Tong A, Sainsbury P, Craig J. Consolidated criteria for reporting qualitative research (COREQ): a 32-item checklist for interviews and focus groups. Int J Qual Health Care 2007;19:349-57.
28. Ramani S, Mann K. Introducing medical educators to qualitative study design: twelve tips from inception to completion. Med Teach 2016;38:456-63.

29. Corbin J, Strauss AL. Basics of qualitative research. 4th edn. Los Angeles: SAGE Publications, 2015.

30. Bertakis KD. The influence of gender on the doctor-patient interaction. Patient Educ Couns 2009;76:356-60.

31. Association of American Medical Colleges. Active physicians by sex and specialty, 2015. Available: https://www.aamc.org/data/ workforce/reports/458712/1-3-chart.html [Accessed 30 Aug 2018].

32. Publication committee of Yearbook of Traditional Korean Medicine. 2016 Yearbook of traditional Korean medicine. Daejeon, Republic of Korea: Korea Institute of Oriental Medicine, 2016.

33. Kim H, Jeong $\mathrm{H}$, Jeon $\mathrm{P}$, et al. Perception study of traditional Korean medical students on the medical education using the Dundee ready educational environment measure. Evid Based Complement Alternat Med 2016;2016:1-7.

34. Nomura K, Yano E, Fukui T. Gender differences in clinical confidence: a nationwide survey of resident physicians in Japan. Acad Med 2010;85:647-53.

35. Jeong H-R, Lee J-H. A study on Korean medicine college students' perception of Korean medicine doctors: focus on gender differences. Journal of Oriental Neuropsychiatry 2015;26:211-24.

36. McKimm J, Da Silva AS, Edwards S, et al. Women and leadership in medicine and medical education: international perspectives. In: Gender, careers and inequalities in medicine and medical education: international perspectives (international perspectives on equality, diversity and inclusion. . Emerald Group Publishing Limited, 2015: 2. 69-98.

37. Heo E. Individualization and Gender Division of Labor : Panel Analysis of Gender Role Attitudes of Women in the Formative Period of a Family. Korean Journal of Sociology 2017;51:47-78.

38. Eun KS. Korean women's labor force participation and career discontinuity. Korean Policy Studies Review 2018;41:117-50.

39. Izumi M, Nomura K, Higaki Y, et al. Gender role stereotype and poor working condition pose obstacles for female doctors to stay in fulltime employment: Alumnae survey from two private medical schools in Japan. Tohoku J Exp Med 2013;229:233-7.

40. Florian SM. Motherhood and employment among whites, Hispanics, and blacks: a life course approach. J Marriage Fam 2018;80:134-49.

41. Smith V, Bethune C, Hurley KF. Examining medical student specialty choice through a gender lens: an orientational qualitative study. Teach Learn Med 2018;30:33-44.

42. Kim S-S, Chung Y, Subramanian SV, et al. Measuring discrimination in South Korea: Underestimating the prevalence of discriminatory experiences among female and less educated workers? PLoS One 2012;7:e32872.

43. Bertakis KD. The influence of gender on the doctor-patient interaction. Patient Educ Couns 2009;76:356-60.

44. Schieber A-C, Delpierre C, Lepage B, et al. Do gender differences affect the doctor-patient interaction during consultations in general practice? results from the INTERMEDE study. Fam Pract 2014;31:706-13.

45. Fennema K, Meyer D, Owen N. Sex of physician: Patients' preferences and stereotypes. J Fam Pract 1990;30:1-7.

46. Himmelstein MS, Sanchez DT. Masculinity in the doctor's office: masculinity, gendered doctor preference and doctor-patient communication. Prev Med 2016;84:34-40.

47. Jefferson L, Bloor K, Spilsbury K. Exploring gender differences in the working lives of UK Hospital consultants. $J$ R Soc Med 2015;108:184-91.

48. Kim MG, Mun WR, Ki DH, et al. 2017 Survey of training and work environment of doctors in training. Seoul: Research Institute for Healthcare Policy, 2017. 